\title{
Human cord blood for the hypoxic-ischemic neonate
}

\author{
James Carroll ${ }^{1}$
}

Autologous umbilical cord blood (UCB) is a possible, but unproven, treatment for acute neonatal brain damage. Mesenchymal stem cells (MSCs), which are present in UCB, are likely to be the treating cell type. UCB is effective in the treatment of neonatal rodent hypoxic-ischemic injury $(\mathrm{HI})$ and other types of brain injury when the cells are delivered acutely. Other types of adult stem cells are similarly effective. However, several negative studies have been reported. The most likely mechanisms of action are participation in blood vessel regeneration, improvement of survival of intrinsic cells, perhaps via neurotrophic factors, or suppression of the release of inflammatory cells from the spleen. In the latter case, the splenic inflammatory cells released at the time of injury are thought to have an adverse effect on brain injury. The timing of the administration of the UCB with respect to the time of the injury appears to be the most important issue: the earlier the better. The risks of autologous administration of UCB are minimal. Current clinical trials with UCB are in progress, but there are no peer-reviewed reports as yet. A multicenter trial with specific inclusion criteria is needed.

$\mathbf{T}$ he efficacy of umbilical cord blood (UCB) cell transplantation for the treatment of human neonatal brain damage is unproven. However, there are several lines of animal experimentation, mainly in rodents, that suggest it might be effective. We will review the existing scientific basis for their potential utility. In particular, we will examine the potential for the use of autologous UCB.

\section{WHAT TYPES OF CELLS DOES UCB CONTAIN?}

$\mathrm{UCB}$ is widely used for the purpose of hematopoietic stem cell replacement therapies. This function is mainly related to its high content of CD34+ cells. For the treatment of brain injury, however, the presence of mesenchymal stem cells (MSCs) appears to be critical. The putative benefit of MSCs was initially predicated on their potential to differentiate into multiple cell lineages and particularly into nerve cell precursors. For example, UCBderived MSCs were shown to develop into neurospheres, which were then induced to develop into oligodendrocyte progenitor cells (1). The expression of surface markers on these cells was consistent with an oligodendrocyte phenotype. CD34 (-) UCB cells stain for MSC markers CD29, CD73, and CD105 (2). These cells, used in this study (2), could be induced to differentiate into at least three lineage cell types: adipocytes, osteoblasts, and chondrocytes. The distinct phenotype of cell markers describing MSCs is not completely agreed upon, but the CD34+ fraction apparently does not contain MSCs (2). Furthermore, as the experimental evidence presented indicates, if there is indeed any benefit, it does not appear to be related to the engraftment or differentiation of the transplanted cells.

\section{EXPERIMENTAL STUDIES WITH UCB IN HYPOXIC-ISCHEMIC INJURY (HI)}

Several studies have reported benefit with UCB treatment of experimental acute neonatal rodent HI (3-5). The model usually employed is a variation on the Rice-Vannuci model with unilateral carotid ligation at $7 \mathrm{~d}$ of age immediately followed by a period of $8 \%$ hypoxia. Neuroprotection was afforded by intraperitoneal transplantation $(3,5)$ or intracerebral administration $(4)$. The time lapse between injury and transplantation was brief in the studies- $3 \mathrm{~h}$ (3), $1 \mathrm{~d}$ (5), or $3 \mathrm{~d}$ in the experiment using intracerebral administration (4). One of these studies (5) found migration but not differentiation of the cells in injured brain. With the intracerebral administration (4), the authors noted differentiation of the transplanted cells into astrocytes but not neurons.

In one particular study, intravenous (i.v.) treatment with UCB was facilitated by the use of mannitol to enhance bloodbrain barrier permeability, and the cells were administered $7 \mathrm{~d}$ after the injury (6). The authors found very few UCB cells in the brain tissue. The overall conclusion of these reports, all of which used an acute treatment protocol, was that the benefit was mediated by trophic factors rather than cell replacement.

Although stem cell administration has not been reported with the rabbit model described by Tan and co-workers $(7,8)$, the model provides some potential advantages over the rodent model for future stem cell experiments. The preborn rabbits are subjected to in utero hypoxia, which results in hypertonic motor disability, a finding generally not detectable in rodent models. In terms of cerebral palsy as a chronic disability, however, the model has not been studied over the long term.

\section{POSITIVE EXPERIMENTAL STUDIES WITH UCB IN OTHER TYPES OF ACUTE BRAIN INJURY \\ Numerous studies have employed UCB in other types of acute brain injury. Most of these reports deal with their effect in}


experimental stroke in adult rats. Chen et al. (9) reported that i.v. administration of human UCB lessened the behavioral deficit after stroke in rats. Greater benefit was observed with administration $24 \mathrm{~h}$ after the injury as opposed to $7 \mathrm{~d}$ after the injury. These authors observed that the UCB survived and migrated in the affected brain. Similarly, Willing et al. (10) found UCB to be beneficial in experimental rat stroke, with i.v. treatment $24 \mathrm{~h}$ after the stroke being more effective than direct striatal delivery. The response to i.v. administration may be dose related, as shown in rats treated $24 \mathrm{~h}$ after stroke (11). Benefit is reported even when the UCB was not found in the brains of treated animals (12). However, there were increased levels of neurotrophic factors in brains of treated animals. In this study, the cells were administered at the same time as the vessel occlusion to produce the stroke. Newcomb et al. demonstrated efficacy of i.v. UCB $48 \mathrm{~h}$ after embolic stroke (13). Another study showed a reduction of infarct volume in dogs subjected to cerebral infarction when the cells were administered $1 \mathrm{~d}$ after the stroke via intra-arterial injection (14).

UCB has also been employed as an experimental treatment in other types of brain injury. UCB given intravenously $24 \mathrm{~h}$ after the injury lessened neurologic deficit in rats with hemorrhagic brain injury (15). Likewise, i.v. UCB administration $24 \mathrm{~h}$ after traumatic brain injury reduced neurological deficits (16).

The general themes of these experiments are: (i) early administration is the most efficacious and (ii) i.v. delivery is at least as effective as direct injection into the brain.

\section{EXPERIMENTAL STUDIES REPORTING LACK OF BENEFIT WITH UCB TREATMENT}

Negative studies are rarely reported, but it is worth noting that there are several negative studies reported with UCB treatment. de Paula et al. (17) found no benefit with UCB in neonatal rat HI. In this study, the animals were treated $24 \mathrm{~h}$ after HI injury via i.v. injection. Very few of the transplanted cells were found in brain. Similarly, Makinen et al. (18) found no benefit of UCB in stroke. These studies were in adult rats subjected to transient middle cerebral artery occlusion, and the UCB was injected intravenously $24 \mathrm{~h}$ after the injury. Once again, very few cells were found in the brain. Similarly, others $(18,19)$ failed to find any benefit with i.v. injection of UCB after stroke in rats. The cells were administered 1, 2, 3, or $7 \mathrm{~d}$ after the injury (19). Minimal numbers of cells were found in the brain. Riegeisberger et al. (20), using UCB in a hypertensive rat model of permanent stroke, failed to produce any lessening of stroke volume using i.v. UCB $24 \mathrm{~h}$ after the injury.

\section{EXPERIMENTAL STUDIES WITH OTHER ADULT STEM CELLS}

Although there are relatively few experimental studies utilizing UCB as a treatment for any type of acute brain injury, there are numerous such studies with other types of adult stem cells. We recently reviewed these studies related to various aspects of brain injury (19) and concluded that these experimental studies demonstrate benefit when the cells are delivered soon after the injury. The route of administration may be either i.v. or intracerebral. The mechanism of benefit is not the replacement of cells, as very few transplanted cells are found at the site of injury.

We employed multipotent adult progenitor cells in experiments with acute neonatal rat HI (21). These cells have the potential to differentiate into mesoderm, neuroectoderm, and endoderm (22). The improvement we observed was obtained by both i.v. and intracerebral transplantation up to $7 \mathrm{~d}$ after the injury (21).

\section{WHAT ARE THE POTENTIAL MECHANISMS OF ACTION?}

The mechanism of action of any UCB benefit in acute HI is unknown. We reviewed the possible mechanisms for the of benefit adult stem cells (23) in HI, which would likely also apply to UCB. The main ideas are: (i) replacement of damaged central nervous system cells, (ii) blood vessel regeneration, (iii) inducement of greater survival of intrinsic cells by noncellular factors, and (iv) action on the spleen to reduce release of inflammatory cells (Figure 1). Although only a small portion of the literature about mechanisms specifically relates to UCB, the work with other types of adult stem cells should also apply to this area.

With regard to cell replacement by the transplanted cells, small numbers of transplanted cells are sometimes reported to survive, but even fewer demonstrate transformation to neural cell types, and the numbers of cells undergoing this process is likely too small to support functional improvement $(21,24,25)$.

Blood vessel regeneration may occur by the stem cells promoting adhesion of CXCR4-positive cells onto vascular endothelium (26), recruitment of endothelial progenitor cells (27), and in the formation of periendothelial vascular cells (28). Borlongan et al. (29) showed in an animal model of stroke that crude bone marrow-derived stem cells may form endothelial cells. Using the HI neonatal rat model, Rosenkranz et al. (30) demonstrated that the chemokine SDF-1/CXCL 12 system contributed to the homing of UCB cells to the site of the injury. SDF-1 was upregulated at the site of injury. Cells expressing the CXCR4 receptor migrated to the site of SDF-1 upregulation within $1 \mathrm{~d}$ after transplant. Increased chemokines in the ischemic area bind cell surface receptors on UCB (31).

Thirdly, we reported that multipotent adult progenitor cells, a variety of adult stem cells, brought about a greater survival of intrinsic neuronal cells (21). A possible mechanism of this outcome was offered with the demonstration (32) that injection of MSCs increased the expression of nerve growth factor and brain-derived neurotrophic factor after traumatic injury (32). Likewise, Xiao et al. (33) reported that UCB acted via trophic factors affecting nerve fiber reorganization. UBC also increase the expression of genes related to oligodendrocyte survival (34).

Finally, another possible mechanism of benefit is the effect of adult stem cells on splenic function during acute brain injury. Vendrame et al. (35) proposed that UCB treatment acted in part in rat stroke by reducing inflammatory response and that the mechanism operated by reducing the splenic release of 


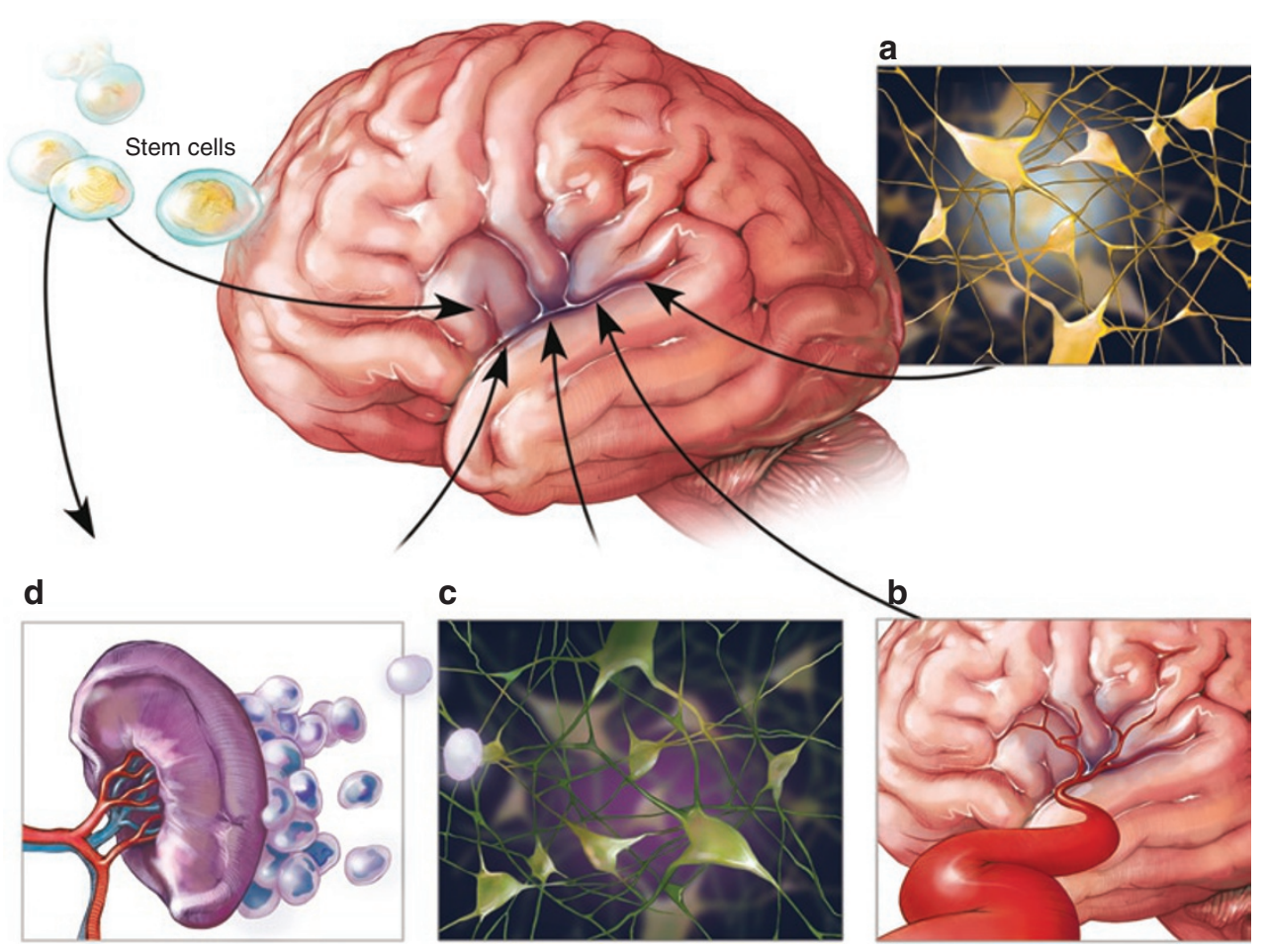

Figure 1. Possible mechanisms of stem cell benefit. (a) Replacement of damaged cells, (b) blood vessel regeneration, (c) greater survival of intrinsic cells, and (d) action on spleen to reduce release of inflammatory cells. Illustration by Colby Polonsky.

inflammatory cells (36), thereby decreasing the inflammatory cells adversely affecting brain following stroke. In support of this concept, Walker et al. (37) demonstrated that the i.v. injection of multipotent adult progenitor cells after trauma blocked the normal splenic response to injury and improved outcome. These reports support the idea that the spleen plays a role in adversely increasing the blood-brain barrier permeability and that the splenic response is blocked by adult stem cell therapy. Once again, this is a benefit only for the acute situation. Ajmo et al. (38) examined the mechanism whereby the splenic reponse to stroke participates in the worsening of stroke, showing that the splenic response is mediated by splenic adrenoreceptors. Leonardo et al. (39) likewise showed that UCB produced a suppression of proinflammatory cells during the process of infarction.

\section{WHAT IS THE TIMING OF ADMINISTRATION?: ACUTE VS.} CHRONIC

All the studies reporting benefit with UCB or other types of adult stem cells deal with the delivery of the cells very soon after the injury, usually within the first week. Their success appears to be dependent on the presence of an acute brain injury and the various acute cellular and noncellular factors that are associated with the acuity of the injury. There do not seem to be any controlled studies using adult to stem cells as a treatment for a brain injury that has entered the chronic stage. Furthermore, the period of time at which acute injury becomes a chronic injury for the purpose of this treatment is not known.

\section{RISKS OF THE TREATMENT}

Most of the risks incurred with UCB therapy would be related to the use of allogeneic cells rather than autologous cells. Allogeneic cells could expose the recipient to graft-versushost disease. The details of matching allogeneic cells would complicate treatment protocols in terms of the requirement to determine how close the match would need to be to insure the necessary degree of safety. Further, the need for immunosuppression would need to be ascertained. We recently reviewed the potential complications as they would occur with nonautologous transplants (23). The other primary risk is the introduction of an infectious agent.

The site of delivery, i.e., the cerebrospinal fluid or the brain itself, as opposed to i.v. delivery, would likely elevate the possibility of adverse reaction. .

Sun et al. (40) have reported the results of 198 autologous UCB infusions in 184 children with different types of neurological disorders, most with the clinical syndrome of cerebral palsy. Three patients had infusion reactions, mainly episodes of wheezing. These occurrences were resolved by discontinuation and treatment with diphenhydramine and bronchodilators.

\section{CURRENT PRACTICE, CURRENT TRIALS}

The current position of the American Academy of Pediatrics (41) on UCB transplantation discourages banking for later personal or family use "because most conditions that might be helped by cord blood stem cells already exist in the infant's cord blood (i.e., premalignant changes in stem cells)." Thus, this policy does not address any potential for the use of autologous 


\section{Review | Carroll}

Table 1. Clinical trials with umbilical cord blood

\begin{tabular}{lllll}
\hline ID number & Organization & Autologous or allogeneic & Acute or chronic injury & Clinical target \\
\hline NCT01147653 & Duke University & Autologous & Chronic & Cerebral palsy \\
NCT01193660 & Sung Kwang Foundation & Allogeneic & Chronic & Cerebral palsy \\
NCT01451528 & Sung Kwang Foundation & Allogeneic & Chronic & Traumatic brain injury \\
NCT01354483 & China Spinal Cord Network & Allogeneic & Chronic & Spinal cord injury \\
NCT01121328 & Ain Shams University & Autologous & Acute & Prevention of developmental delay \\
NCT01046786 & China Spinal Cord Network & Allogeneic & Chronic & Spinal cord injury \\
NCT01354483 & China Spinal Cord Network & Allogeneic & Chronic & Spinal cord injury \\
NCT01072370 & Georgia Health Sciences University & Autologous & Chronic & Cerebral palsy \\
NCT00593242 & Duke University & Autologous & Acute & Neonatal hypoxic-ischemic injury \\
NCT01251003 & University of Texas & Autologous & Chronic & Traumatic brain injury \\
NCT01343394 & Memorial Hermann Healthcare & Autologous & Chronic & Acquired hearing loss \\
\hline
\end{tabular}

UCB after birth for the purpose of treating either the acute or longstanding effects of neonatal brain damage. This policy is quite proper, as this usage of UCB currently remains unproven.

There are a number of trials that utilize UCB in children with various types of brain injuries. These trials (http://clinicaltrials. gov) are shown in Table 1. Only one, at Duke University, tests the effect of autologous cord blood infusion on acute neonatal brain damage. No results are available. The other acute treatment trial, at Ain Shams University in Egypt for the purpose of preventing developmental delay in preterm infants, is not yet recruiting.

The other trials noted in the table using UCB are to test the treatment in chronic injuries of various types. Thus, these trials are somewhat indirect with regard to acute neonatal brain damage because they test the effects of UCB in long-standing brain injuries. There are two US trials, one at Georgia Health Sciences University and the other at Duke University, dealing with cerebral palsy as the clinical target. Only a minor percentage of these children have likely had their condition arise from acute neonatal brain damage.

The trial at Georgia Health Sciences University accepts patients from 1 to $12 \mathrm{y}$ of age with the diagnosis of cerebral palsy with inability to walk before $18 \mathrm{mo}$ of age. The children must have a sufficient amount of UCB stored according to the weight of the child. Children with hydrocephalus, progressive neurological disease, disorders of brain development, major congenital anomaly, or known genetic disorder are excluded. This is a randomized, crossover trial with both treatment groups receiving UCB but at different points in the study. A standardized questionnaire and motor ability assessment are the important outcome measures.

The Duke University study accepts patients from 1 to $6 \mathrm{y}$ of age with spastic type cerebral palsy and a sufficient amount of UCB in storage. Exclusion criteria are athetoid cerebral palsy, autism, progressive neurologic disease, severe microcephaly, or known genetic disorder. This is a randomized, crossover study similar to the Georgia study with the addition of brain magnetic resonance imaging and assessment of cytokine activity in the infused UCB.
No peer-reviewed results are available for these trials. In view of the fact that cerebral palsy is comprised of many different etiologies, firm conclusions from these studies will likely be very difficult. In terms of attempting to deal with the possible benefit of UCB in long-standing neonatal brain damage, the study would need to be confined to children who have sustained cerebral palsy as a result of HI injury. In order to include the necessary number of subjects with cerebral palsy due to long-standing $\mathrm{HI}$ injury, a multiple center trial would be needed. The difficulty of such a study would be compounded by the fact that most of these patients would not have autologous UCB available. Also, the presence of HI injury would need to be carefully defined.

A similar trial (NCT01251003) that deals with the use of UCB in children who suffered traumatic brain injury in the period 6-18 mo after injury is under way at the University of Texas Health Science Center in Houston, Texas.

\section{WHAT'S NEEDED IN THE FIELD?}

In view of the experimental evidence in rodents that $\mathrm{UCB}$ improves the outcome from acute neonatal $\mathrm{HI}$ injury, similar lines of research with adult stem cell preparations in other types of acute brain injury, and the lack of serious safety concerns about the use of autologous UCB intravenous infusion, a clinical trial is indicated.

The trial should include only term infants meeting clear-cut criteria for acute HI, including: (i) a definite injury, demarcated by a cord blood pH less than 7.0, (ii) a clinical course in the neonatal period that is consistent with $\mathrm{HI}$ injury, including the early onset of seizures, and of specifically defined severity, and (iii) the absence of any other cause.

Given the probable reluctance of some of the involved parties to come to an agreement early on with respect to the diagnosis of HI injury (because of the appropriate fear of litigation), the acquisition of subjects at any one institution would likely be very difficult. Therefore, a multicenter trial would be needed.

\section{STATEMENT OF FINANCIAL SUPPORT}

The author is supported by the National Institute of Neurological Disorders and Stroke (5R42NS55606) and Athersys, Inc. 


\section{REFERENCES}

1. Luo YC, Zhang HT, Cheng HY, Yang ZJ, Dai YW, Xu RX. Differentiation of cryopreserved human umbilical cord blood-derived stromal cells into cells with an oligodendrocyte phenotype. In Vitro Cell Dev Biol Anim 2010;46:585-9.

2. Lu X, Alshemali S, de Wynter EA, Dickinson AM. Mesenchymal stem cells from CD34(-) human umbilical cord blood. Transfus Med 2010;20:178-84.

3. Pimentel-Coelho PM, Magalhães ES, Lopes LM, deAzevedo LC, Santiago MF, Mendez-Otero R. Human cord blood transplantation in a neonatal rat model of hypoxic-ischemic brain damage: functional outcome related to neuroprotection in the striatum. Stem Cells Dev 2010;19:351-8.

4. Xia G, Hong X, Chen X, Lan F, Zhang G, Liao L. Intracerebral transplantation of mesenchymal stem cells derived from human umbilical cord blood alleviates hypoxic ischemic brain injury in rat neonates. J Perinat Med 2010;38:215-21.

5. Meier C, Middelanis J, Wasielewski B, et al. Spastic paresis after perinatal brain damage in rats is reduced by human cord blood mononuclear cells. Pediatr Res 2006;59:244-9.

6. Yasuhara T, Hara K, Maki M, et al. Mannitol facilitates neurotrophic factor up-regulation and behavioural recovery in neonatal hypoxicischaemic rats with human umbilical cord blood grafts. J Cell Mol Med 2010;14:914-21.

7. Derrick M, Luo NL, Bregman JC, et al. Preterm fetal hypoxia-ischemia causes hypertonia and motor deficits in the neonatal rabbit: a model for human cerebral palsy? J Neurosci 2004;24:24-34.

8. Derrick M, Drobyshevsky A, Ji X, et al. Hypoxia-ischemia causes persistent movement deficits in a perinatal rabbit model of cerebral palsy: assessed by a new swim test. Int J Dev Neurosci 2009;27:549-57.

9. Chen J, Sanberg PR, Li Y, et al. Intravenous administration of human umbilical cord blood reduces behavioral deficits after stroke in rats. Stroke 2001;32:2682-8.

10. Willing AE, Lixian J, Milliken M, et al. Intravenous versus intrastriatal cord blood administration in a rodent model of stroke. J Neurosci Res 2003;73:296-307.

11. Vendrame M, Cassady J, Newcomb J, et al. Infusion of human umbilical cord blood cells in a rat model of stroke dose-dependently rescues behavioral deficits and reduces infarct volume. Stroke 2004;35:2390-5.

12. Borlongan CV, Hadman M, Sanberg CD, Sanberg PR. Central nervous system entry of peripherally injected umbilical cord blood cells is not required for neuroprotection in stroke. Stroke 2004;35:2385-9.

13. Newcomb JD, Ajmo CT Jr, Sanberg CD, Sanberg PR, Pennypacker KR, Willing AE. Timing of cord blood treatment after experimental stroke determines therapeutic efficacy. Cell Transplant 2006;15:213-23.

14. Chung DJ, Choi CB, Lee SH, et al. Intraarterially delivered human umbilical cord blood-derived mesenchymal stem cells in canine cerebral ischemia. J Neurosci Res 2009;87:3554-67.

15. Nan Z, Grande A, Sanberg CD, Sanberg PR, Low WC. Infusion of human umbilical cord blood ameliorates neurologic deficits in rats with hemorrhagic brain injury. Ann N Y Acad Sci 2005;1049:84-96.

16. Lu D, Sanberg PR, Mahmood A, et al. Intravenous administration of human umbilical cord blood reduces neurological deficit in the rat after traumatic brain injury. Cell Transplant 2002;11:275-81.

17. de Paula S, Vitola AS, Greggio S, et al. Hemispheric brain injury and behavioral deficits induced by severe neonatal hypoxia-ischemia in rats are not attenuated by intravenous administration of human umbilical cord blood cells. Pediatr Res 2009;65:631-5.

18. Mäkinen S, Kekarainen T, Nystedt J, et al. Human umbilical cord blood cells do not improve sensorimotor or cognitive outcome following transient middle cerebral artery occlusion in rats. Brain Res 2006;1123:207-15.

19. Zawadzka M, Lukasiuk K, Machaj EK, Pojda Z, Kaminska B. Lack of migration and neurological benefits after infusion of umbilical cord blood cells in ischemic brain injury. Acta Neurobiol Exp (Wars) 2009;69:46-51.

20. Riegelsberger UM, Deten A, Pösel C, et al. Intravenous human umbilical cord blood transplantation for stroke: impact on infarct volume and caspase-3-dependent cell death in spontaneously hypertensive rats. Exp Neurol 2011;227:218-23.
21. Yasuhara T, Hara K, Maki M, et al. Intravenous grafts recapitulate the neurorestoration afforded by intracerebrally delivered multipotent adult progenitor cells in neonatal hypoxic-ischemic rats. J Cereb Blood Flow Metab 2008;28:1804-10.

22. Jiang Y, Jahagirdar BN, Reinhardt RL, et al. Pluripotency of mesenchymal stem cells derived from adult marrow. Nature 2002;418:41-9.

23. Carroll JE, Mays RW. Update on stem cell therapy for cerebral palsy. Expert Opin Biol Ther 2011;11:463-71.

24. Riess P, Zhang C, Saatman KE, et al. Transplanted neural stem cells survive, differentiate, and improve neurological motor function after experimental traumatic brain injury. Neurosurgery 2002;51:1043-52; discussion 1052-4.

25. Zhao LR, Duan WM, Reyes M, Keene CD, Verfaillie CM, Low WC. Human bone marrow stem cells exhibit neural phenotypes and ameliorate neurological deficits after grafting into the ischemic brain of rats. Exp Neurol 2002;174:11-20.

26. Peled A, Kollet O, Ponomaryov T, et al. The chemokine SDF-1 activates the integrins LFA-1, VLA-4, and VLA-5 on immature human CD34(+) cells: role in transendothelial/stromal migration and engraftment of NOD/SCID mice. Blood 2000;95:3289-96.

27. Yamaguchi J, Kusano KF, Masuo O, et al. Stromal cell-derived factor-1 effects on ex vivo expanded endothelial progenitor cell recruitment for ischemic neovascularization. Circulation 2003;107:1322-8.

28. Rajantie I, Ilmonen M, Alminaite A, Ozerdem U, Alitalo K, Salven P. Adult bone marrow-derived cells recruited during angiogenesis comprise precursors for periendothelial vascular mural cells. Blood 2004;104:2084-6.

29. Borlongan CV, Lind JG, Dillon-Carter O, et al. Bone marrow grafts restore cerebral blood flow and blood brain barrier in stroke rats. Brain Res 2004;1010:108-16.

30. Rosenkranz K, Kumbruch S, Lebermann K, et al. The chemokine SDF-1/ CXCL12 contributes to the 'homing' of umbilical cord blood cells to a hypoxic-ischemic lesion in the rat brain. J Neurosci Res 2010;88:1223-33.

31. Jiang L, Newman M, Saporta S, et al. MIP-1alpha and MCP-1 Induce Migration of Human Umbilical Cord Blood Cells in Models of Stroke. Curr Neurovasc Res 2008;5:118-24.

32. Zhang P, Li J, Liu Y, Chen X, Kang Q. Transplanted human embryonic neural stem cells survive, migrate, differentiate and increase endogenous nestin expression in adult rat cortical peri-infarction zone. Neuropathology 2009;29:410-21.

33. Xiao J, Nan Z, Motooka Y, Low WC. Transplantation of a novel cell line population of umbilical cord blood stem cells ameliorates neurological deficits associated with ischemic brain injury. Stem Cells Dev 2005;14:722-33.

34. Rowe DD, Leonardo CC, Hall AA, et al. Cord blood administration induces oligodendrocyte survival through alterations in gene expression. Brain Res 2010;1366:172-88.

35. Vendrame M, Gemma C, de Mesquita D, et al. Anti-inflammatory effects of human cord blood cells in a rat model of stroke. Stem Cells Dev 2005;14:595-604.

36. Vendrame M, Gemma C, Pennypacker KR, et al. Cord blood rescues stroke-induced changes in splenocyte phenotype and function. Exp Neurol 2006;199:191-200.

37. Walker PA, Shah SK, Jimenez F, et al. Intravenous multipotent adult progenitor cell therapy for traumatic brain injury: preserving the blood brain barrier via an interaction with splenocytes. Exp Neurol 2010;225:341-52.

38. Ajmo CT Jr, Collier LA, Leonardo CC, et al. Blockade of adrenoreceptors inhibits the splenic response to stroke. Exp Neurol 2009;218:47-55.

39. Leonardo CC, Hall AA, Collier LA, Ajmo CT Jr, Willing AE, Pennypacker KR. Human umbilical cord blood cell therapy blocks the morphological change and recruitment of CD11b-expressing, isolectin-binding proinflammatory cells after middle cerebral artery occlusion. J Neurosci Res 2010;88:1213-22.

40. Sun J, Allison J, McLaughlin C, et al. Differences in quality between privately and publicly bsanked umbilical cord blood units: a pilot study of autologous cord blood infusion in children with acquired neurologic disorders. Transfusion 2010;50:1980-7.

41. Section on Hematology/Oncology and Section on Allergy/Immunology. Cord blood banking for potential future transplantation. Pediatrics 2007;119:165-70. 